\title{
GÉNERO EN EL DISCURSO: DISCRIMINACIÓN. MALTRATO A LA MUJER
}

\author{
Nuria del Mar Torres López \\ Mª del Pilar Díaz-López \\ Universidad de Almería
}

https://doi.org/10.17060/ijodaep.2017.n1.v4.1056

Fecha de Recepción: 11 Marzo 2017

Fecha de Admisión: 1 Abril 2017

\section{RESUMEN}

A través del presente trabajo se ofrece una visión generalizada sobre uno de los temas, desgraciadamente, de mayor actualidad y vital relevancia como es el tema del maltrato a la mujer en distintos ámbitos. Hemos seleccionado este tema para contrastarlo con diversos datos, fruto de una breve investigación, y serán relacionados con algunas de las referencias con las que la Doctora Encarnación Hidalgo ${ }^{1}$ obsequió a los asistentes durante las sesiones que impartió en el Máster ${ }^{2}$ en estudios de género en la Universidad de Almería, como es el caso de la discriminación de la mujer a través del discurso.

Palabras claves: violencia, género, discurso, mujeres, maltrato, discriminación

\section{INTRODUCCIÓN}

Por desgracia la discriminación y violencia contra las mujeres, sea de la índole que sea, se ha convertido en problema social que nos incumbe a todos/as y sobre el que debemos tomar conciencia.

Para ello ofreceremos un brevísimo recorrido entre los distintos tipos de violencia que se dan contra las mujeres con el fin de aclarar las diferencias existentes entre los términos que la engloban para finalmente contrastarlos con los diversos casos de maltrato hacía la mujer que se pueden encontrar en la red, concretamente nos centraremos en un artículo titulado Discurso, Género y Violencia Intrafamiliar en la historia de México ${ }^{3}$, que nos sirve para tomarlo como ejemplo que acredita y refleja lo que a diario encontramos en nuestra sociedad, sociedad patriarcal sin lugar a dudas, independientemente del país que sea. Finalmente se añadirán algunas notas sobre la discriminación, claramente visible, que sufre la mujer a través del discurso.

Porque la "lucha" de algunos hombres, contra la mujer, sus principios e inquietudes y contra lo que son capaces de llegar a ser, si se eliminan las barreras aún existentes, ni cesa ni encuentra des- 


\section{GÉNERO EN EL DISCURSO: DISCRIMINACIÓN. MALTRATO A LA MUJER}

canso, y lo que es peor, algunos deciden hacer uso de la vía más "fácil” y a su vez la más cobarde para destruir a la mujer, es decir, la violencia.

\section{OBJETIVOS}

Ofrecer un breve estudio de los diferentes tipos de maltrato sufridos por la mujer verbalmente a través del discurso en este caso, por parte del hombre.

Concienciar a la sociedad de la situación actual de discriminación que aún, en pleno siglo XXI, sufren las mujeres.

Sensibilizar y dejar constancia de la relevancia que la educación tiene como núcleo formador para atenuar y erradicar la violencia hacia las mujeres.

Analizar artículos y textos sobre el discurso, género y violencia contra las mujeres.

\section{METODOLOGÍA}

Tras presentar un conciso estudio sobre los diversos tipos de maltrato, sus tipologías y características, procederemos a analizar, tras la observación de textos y artículos, diferentes modos de maltrato ejercido a las mujeres (a través de los siglos) en forma de discursos.

\section{VIOLENCIA CONTRA LA MUJER: DIFERENTES TÉRMINOS}

En general, para hacer alusión a una de las definiciones más consolidadas de violencia contra las mujeres podemos recurrir a la siguiente: "todo acto de violencia sexista que tiene como resultado posible o real un daño físico, sexual o psíquico, incluidas las amenazas, la coerción o la privación arbitraria de libertad, ya sea que ocurre en la vida pública o en la privada" (ONU 1995).

Cuando hablamos de malos tratos, nos encontramos generalmente con diversidad de criterios sobre el propio concepto de maltrato de acuerdo con variables espaciales, temporales y culturales llegándose, a veces, a que un mismo caso pueda ser considerado como tal en función de las personas que lo detecten o investiguen [...] Los malos tratos hacia la mujer son los que se producen en el ámbito familiar o doméstico, privado por tanto, y en el contexto del propio domicilio, por parte de un agresor que tiene un vínculo afectivo con la mujer maltratada (marido, compañero, padre, hermano o hijo). (Instituto de la Mujer, 1991, p.32-33) 4

No obstante, debemos profundizar entre los diversos tipos de maltrato que desde siglos atrás se vienen ejerciendo contra las mujeres. Queda en absoluta evidencia que sea de la índole que sea, esta violencia debe ser condenada y para combatirla debemos unirnos hombres y mujeres.

Violencia de género: tiene que ver con "la violencia que se ejerce hacia las mujeres por el hecho de serlo", e incluye tanto malos tratos de la pareja, como agresiones físicas o sexuales de extraños, mutilación genital, infanticidios femeninos, etc. (García Hernández $z^{5} 2001$ ).

Sin embargo, en 2003 Velázquez ${ }^{6}$ amplía esta definición de violencia de género: "Abarca todos Ios actos mediante los cuales se discrimina, ignora, somete y subordina a las mujeres en los diferentes aspectos de su existencia. Es todo ataque material y simbólico que afecta su libertad, dignidad, seguridad, intimidad e integridad moral y/o física".

Violencia doméstica: hace referencia a aquella que se produce dentro del hogar, tanto del marido a su esposa, como de la madre a sus hijos, del nieto al abuelo, etc. y excluye aquellas relaciones de pareja en las que no hay convivencia. La violencia doméstica es aquella que tiene lugar en el ámbito familiar, no solo entre las cuatro paredes de una casa. El término familiar habrá de entenderse también en sentido amplio. Normalmente se considera que la violencia doméstica se da entre adultos de una edad similar 0 de descendientes a ascendientes. 
Violencia psíquica: esta categoría de violencia es la más citada en todos los estudios. Conduce sistemáticamente a la depresión y a veces, incluso, al suicidio.

Algunos hombres no golpean a sus compañeras, pero las hacen víctimas cargándolas de reproches continuos y amenazas, lo cual las hace mantenerse en un clima de angustia y destruye su equilibrio psicológico. El terror psíquico persiste bajo la forma de la amenaza, del espionaje y de los interrogatorios en un tercer grado que sufren las mujeres. (Instituto de la mujer, 1991, p. 54) 7

Violencia sexual: "Se ejerce mediante presiones físicas o psíquicas que pretenden imponer una relación sexual no deseada mediante coacción, intimidación o indefensión" (Alberdi y Matas ${ }^{8}$, 2002).

Violencia física: La violencia física es aquella que puede ser percibida objetivamente por otros, que más habitualmente deja huellas externas. Esta se refiere a empujones, mordiscos, patadas, puñetazos etc., causados por las manos 0 algún objeto 0 arma. Este tipo de violencia es la más visible y por tanto facilita la toma de conciencia de la víctima, pero también ha supuesto que sea la más reconocida social y jurídicamente, en relación fundamentalmente con la violencia psicológica que supone insultos, humillaciones, amenazas, desprecio hacia la propia mujer...

El primer golpe que recibe una mujer es por un motivo sin importancia (celos, llegadas tarde, etc.), pero en general no se trata de un simple accidente. La frecuencia de los golpes se va a ir acelerando y la violencia acentuando [...] la violencia física puede ser cíclica o cotidiana. (Instituto de la Mujer, 1991, p. 54)

Violencia intrafamiliar: conjunto de actos dirigidos a causar daños, se ejerce a través de maltrato físico, psicoemocional o sexual, dentro o fuera de la familia y se dirige principalmente hacia mujeres, niñas y niños, personas con discapacidades y adultos mayores. (Está será principalmente nombrada al analizar uno de los artículos que nos ocupa).

\section{VIOLENCIA INTRAFAMILIAR: EL MALTRATO A LA MUJER A TRAVÉS DE LA VIOLENCIA. DISCURSOS.}

Como ya especificamos al comienzo del trabajo que nos ocupa esta sección estará dedicada al análisis de algunas fuentes que fácilmente pueden encontrarse en Internet cuando buscamos información sobre los diversos tipos de maltrato que la mujer recibe por parte del hombre.

Nosotros anunciábamos en la introducción que nos basaremos en el que lleva por título Discurso, Género y Violencia Intrafamiliar en la historia de México ya que consideramos que cubre totalmente los distintos objetivos que esta humilde investigación tiene la pretensión de alcanzar. Además, desgraciadamente, aunque este artículo que utilizamos como referente se sitúe en la historia moderna de México, nos sirve para contrastar dichos datos con cualquier otra ciudad y país ya que ese tipo de violencia y discriminación hacia la mujer se extiende por todo el planeta.

Yo [je] discurso, o sujeto-saber, en la acepción que nosotros le damos a este último término, tiene un fundamento idéntico en todo sujeto mientras nos situamos fuera del campo de la psicosis: permite una definición que juzgamos verdadera, pero ello mismo implica que solo lo es a partir de determinado nivel de elaboración de la psique y con la condición de que en el trascurso de esta etapa el sujeto haya logrado superar ciertos escollos (Aulagnier, 1975: 14). 


\section{GÉNERO EN EL DISCURSO: DISCRIMINACIÓN. MALTRATO A LA MUJER}

Animamos desde aquí a hacer una lectura de un artículo llamado Provocando la reflexión sobre el discurso "violencia contra la mujer"9, dónde concretamente el capítulo III está dedicado a las conexiones entre el discurso sobre la violencia y las acciones, incluyendo una sección que analiza la formación del discurso sobre la violencia y otra sobre los logros y desafíos de la década del 90.

Nos centramos ahora en el artículo ya citado sobre el discurso, género y violencia intrafamiliar. Básicamente lo que hace la autora, Marcela Suárez $(2004)^{10}$, en este artículo es informarnos sobre la actual y tristemente, aún existente violencia por parte del varón a las mujeres dentro de las familias. Es una muestra del empoderamiento que aún los hombres ejercen sobre las mujeres ya sea a través del marido a su esposa, como del hijo a la madre... La cuestión es que queda aquí bien reflejado que el hombre, aún en el siglo XXI, sigue considerándose superior a la mujer, razonamiento equívoco y empleado erróneamente para justificar el trato que le dan únicamente debido a la diferencia sexual que existe entre ellos/as.

Queda patente que la educación que el varón haya recibido desde niño jugará un papel fundamental en el rol que este desempeñe cuando sea adulto y conviva con su pareja, ya que la perspectiva del género actúa sobre las concepciones de la familia. La familia se convierte en la reproductora principal de la construcción del género, incluidas, por tanto, las relaciones de dominación. En cuanto a esto afirma Mabel Burin (1978) ${ }^{11}$, doctora en Psicología Clínica y psicoanalista, especialista en Género y Salud Mental.: "la identidad de género se adquiere en la intersubjetividad en los vínculos tempranos de padres e hijos [...] los valores son introyectados al sujeto dentro de la familia y son por tanto base fundamental en la construcción de la subjetividad" (pp.78-80).

Obviamente el discurso ofrecido por diversas instituciones, por la Iglesia, por el gobierno, etc. ha ido contribuyendo a que este pensamiento machista no haya hecho más que ir consolidándose a lo largo de los siglos. Si todo este tipo de creencias ya eran lo suficientemente firmes como para seguir apoyando una sociedad patriarcal sólo faltaba alimentarlos con discursos que meramente exaltaban la imagen de una mujer recatada, hogareña cuyo único interés era conseguir marido para ser así aceptada en la sociedad.

La honestidad femenina se calificaba con su conducta sexual y era censurable que las mujeres salieran a la calle por las noches; durante el día el que las mujeres se sentaran en la puerta de su casa o frecuentaran peluquerías era motivo de escándalo y murmuraciones y apara quienes mostraran estas conductas no había defensa en caso de violación [...] El discurso de la Iglesia asociaba el castigo físico ${ }^{12}$ a la purificación y es posible que ello haya sido interiorizado por algunos hombres y mujeres, ellos para ejercerlo y ellas para soportarlo, pero más bien esta situación podría inscribirse en el discurso masculino sobre poder y dominio. (Suárez, 2004).

Afortunadamente los discursos sobre el género han ido cambiando como fruto del esfuerzo, sacrificio y siglos de lucha que ha mantenido y seguimos manteniendo las mujeres. La autora nos muestra algunos ejemplos que citamos a continuación:

Después de la lucha por la independencia los discursos que se construyeron durante el siglo XIX presentaron una ambivalencia entre la creencia en un nuevo orden social que requería de una familia disciplinada que constituyera la base de este nuevo orden [...] Silvia Arrom (1988) ${ }^{13}$ señala que los discursos coloniales continuaron interiorizados en las mentalidades y como el Derecho Español en gran medida continuó vigente, las mujeres continuaron con sus derechos restringidos sobre la tutoría de los hijos, la participación política y las transacciones legales, y a pesar de que algunos pensadores plantearon la necesidad de cambios, las leyes españolas que favorecían la autoridad 
masculina sobre las mujeres y menores continuaron vigentes hasta la promulgación del Código Civil de 1870.

Los discursos sobre el género manifestados en la opinión pública, en la educación y legislación, fueron producto durante todo el siglo XIX y las primeras décadas del XX- de un sincretismo entre las ideas coloniales y el pensamiento liberal que fue la base para la construcción del moderno Estado Mexicano.

El pensamiento positivista participó directamente a través de los discursos en la construcción de las identidades femeninas y masculinas destinando a las mujeres las actividades de madres, esposas y educadoras dentro del hogar [...]Se consideraba que las mujeres tenían sólo capacidad para realizar actividades "propias de su sexo", dejando a los varones los papeles activos; esto se difundió en Iglesias, discursos legales, prensa, escuelas y para las mujeres de la élite, en manuales de urbanidad. (2004).

Sin duda la situación ha evolucionado y el trato que recibe la mujer hoy, en pleno siglo XXI, difiere mucho del que se le daba antiguamente. No obstante, no cabe duda y es necesario señalar que no en todas las partes del mundo estos cambios han tenido la misma repercusión.

Tabla 1:

Detalles de 16 casos de un total de 52 víctimas reconocidas de la violencia machista en España.

\begin{tabular}{|c|c|c|c|c|c|c|}
\hline Víctima & Edad & Municipio & Provincia & CC.AA. & Fecha & Detalles \\
\hline M. C. R. & 43 & Madrid & $\begin{array}{l}\text { Provincia de } \\
\text { Madrid }\end{array}$ & $\begin{array}{l}\text { Comunidad } \\
\text { de Madrid }\end{array}$ & $\begin{array}{l}2016-01- \\
04\end{array}$ & $\begin{array}{l}\text { Una mujer de } 43 \text { años es } \\
\text { estrangulada por su pareja } \\
\text { en Madrid. [1] }\end{array}$ \\
\hline S. G. S. & 33 & Galápagos & $\begin{array}{l}\text { Provincia de } \\
\text { Guadalajara }\end{array}$ & $\begin{array}{l}\text { Castilla-La } \\
\text { Mancha }\end{array}$ & $\begin{array}{l}2016-01- \\
05\end{array}$ & $\begin{array}{l}\text { Una mujer de } 33 \text { años es } \\
\text { apuñalada por su pareja en } \\
\text { Guadalajara. [2] }\end{array}$ \\
\hline M. P. G. & 19 & Alange & $\begin{array}{l}\text { Provincia } \\
\text { Badajoz }\end{array}$ & Extremadura & $\begin{array}{l}2016-01- \\
07\end{array}$ & $\begin{array}{l}\text { Una mujer aparece muerta } \\
\text { en el pantano de Alange } \\
\text { (Badajoz), presenta golpes, } \\
\text { detienen a un hombre. [3] }\end{array}$ \\
\hline L. E. & 43 & Vila-Seca & $\begin{array}{l}\text { Provincia } \\
\text { Tarragona }\end{array}$ & Cataluña & $\begin{array}{l}2016-01- \\
13\end{array}$ & $\begin{array}{l}\text { Asesina a se ex mujer y } \\
\text { luego se suicida. Tenian } \\
\text { dos hijas. [4] }\end{array}$ \\
\hline M. S. G. & 73 & Valencia & $\begin{array}{l}\text { Provincia } \\
\text { València }\end{array}$ & $\begin{array}{l}\text { Comunidad } \\
\text { Valenciana }\end{array}$ & $\begin{array}{l}2016-01- \\
22\end{array}$ & $\begin{array}{lrcrc}\text { Golpea y } & \text { degüiella } & \text { a } & \text { su } \\
\text { mujer y } & \text { luego } & & \text { se } \\
\text { suicida. [5] } & & & \end{array}$ \\
\hline L. J. L. & 49 & Calvià & $\begin{array}{l}\text { Provincia } \\
\text { Baleares }\end{array}$ & Islas Baleares & $\begin{array}{l}2016-01- \\
23\end{array}$ & $\begin{array}{l}\text { Mujer es estrangulada por } \\
\text { su marido. [6] }\end{array}$ \\
\hline A. A. & 46 & Avilés & $\begin{array}{l}\text { Provincia } \\
\text { Asturias }\end{array}$ & $\begin{array}{l}\text { Principado de } \\
\text { Asturias }\end{array}$ & $\begin{array}{l}2016-01- \\
27\end{array}$ & $\begin{array}{l}\text { Asesinada a golpes por su } \\
\text { marido. [7] }\end{array}$ \\
\hline A. G. N. & 40 & Becerreá & $\begin{array}{l}\text { Provincia de } \\
\text { Lugo }\end{array}$ & Galicia & $\begin{array}{l}2016-02- \\
11\end{array}$ & $\begin{array}{l}\text { Mata a su pareja de un tiro } \\
\text { delante de sus hijos. [8] }\end{array}$ \\
\hline Francisca & 71 & Valencia & $\begin{array}{l}\text { Provincia de } \\
\text { València }\end{array}$ & $\begin{array}{l}\text { Comunidad } \\
\text { Valenciana }\end{array}$ & $\begin{array}{l}2016-02- \\
13\end{array}$ & $\begin{array}{l}\text { Hombre estrangula a su } \\
\text { mujer. [9] }\end{array}$ \\
\hline Soraya & 37 & Zaragoza & $\begin{array}{l}\text { Provincia } \\
\text { Zaragoza }\end{array}$ & Aragón & $\begin{array}{l}2016-02- \\
22\end{array}$ & $\begin{array}{l}\text { Hombre asesina a tiros a su } \\
\text { ex pareja y luego se } \\
\text { suicida. }[10]\end{array}$ \\
\hline $\begin{array}{l}\text { Victoria S. } \\
\text { M. }\end{array}$ & 19 & Son Servera & $\begin{array}{l}\text { Provincia de } \\
\text { Baleares }\end{array}$ & Islas Baleares & $\begin{array}{l}2016-03- \\
11\end{array}$ & {$\left[\begin{array}{ll}1 & 1\end{array}\right]$} \\
\hline
\end{tabular}




\section{GÉNERO EN EL DISCURSO: DISCRIMINACIÓN. MALTRATO A LA MUJER}

\begin{tabular}{|c|c|c|c|c|c|c|}
\hline Víctima & Edad & Municipio & Provincia & CC.AA. & Fecha & Detalles \\
\hline S. H. A. & 34 & Gijón & $\begin{array}{l}\text { Provincia de } \\
\text { Asturias }\end{array}$ & $\begin{array}{l}\text { Principado de } \\
\text { Asturias }\end{array}$ & $\begin{array}{l}2016-03- \\
14\end{array}$ & {$\left[\begin{array}{ll}1 & 2\end{array}\right]$} \\
\hline Cristina & 36 & $\begin{array}{l}\text { Sant Feliu de } \\
\text { Lobregat }\end{array}$ & $\begin{array}{l}\text { Provincia de } \\
\text { Barcelona }\end{array}$ & Cataluña & $\begin{array}{l}2016-04- \\
14\end{array}$ & $\begin{array}{l}\text { Un mosso d'Esquadra } \\
\text { asesina a su expareja en } \\
\text { Barcelona. }[13]\end{array}$ \\
\hline Yolanda & 45 & Salamanca & $\begin{array}{l}\text { Provincia de } \\
\text { Salamanca }\end{array}$ & $\begin{array}{l}\text { Castilla } \quad y \\
\text { León }\end{array}$ & $\begin{array}{l}2016-04- \\
17\end{array}$ & [14] \\
\hline R. R. A. & 72 & Zaragoza & $\begin{array}{l}\text { Provincia de } \\
\text { Zaragoza }\end{array}$ & Aragón & $\begin{array}{l}2016-05- \\
08\end{array}$ & $\begin{array}{l}\text { Mata a su mujer a } \\
\text { martillazos en la cabeza } \\
\text { hiere a su hijo. }[15]\end{array}$ \\
\hline M. C. G. & 50 & $\begin{array}{l}\text { Santa Cruz de } \\
\text { Tenerife }\end{array}$ & $\begin{array}{l}\text { Provincia de } \\
\text { Santa Cruz de } \\
\text { Tenerife }\end{array}$ & Canarias & $\begin{array}{l}2016-05- \\
11\end{array}$ & $\begin{array}{l}\text { Una mujer es estrangulada } \\
\text { por su marido. La víctima } \\
\text { llevaba } \\
\text { denunciando. }[16]\end{array}$ \\
\hline L. $\mathbf{P}$. & 47 & $\begin{array}{l}\text { Puerto de } \\
\text { Pollença }\end{array}$ & $\begin{array}{l}\text { Provincia de } \\
\text { Baleares }\end{array}$ & Islas Baleares & $\begin{array}{l}2016-05- \\
29\end{array}$ & $\begin{array}{l}\text { Una mujer es apuñalada por } \\
\text { su pareja. [17] }\end{array}$ \\
\hline$?$ & 32 & Sevilla & $\begin{array}{l}\text { Provincia de } \\
\text { Sevilla }\end{array}$ & Andalucía & $\begin{array}{l}2016-06- \\
02\end{array}$ & $\begin{array}{l}\text { Una mujer es asesinada por } \\
\text { su pareja en Sevilla. [18] }\end{array}$ \\
\hline
\end{tabular}

Tabla 2:

Número de víctimas asesinadas en lo que va de año (- junio, 2017). ${ }^{14}$

\begin{tabular}{|c|c|c|c|}
\hline \multicolumn{4}{|c|}{ TOTAL FEMINICIDIOS Y OTROS ASESINATOS DE MUJERES 2017: } \\
\hline \multicolumn{4}{|c|}{54} \\
\hline ENERO: 8 & FEBRERO: 15 & MARZO: 12 & ABRIL: 9 \\
\hline MAYO: 7 & JUNIO: 3 & JULIO: & AGOSTO: \\
\hline SEPTIEMBRE: & OCTUBRE: & NOVIEMBRE: & DICIEMBRE: \\
\hline
\end{tabular}

\section{DISCRIMINACIÓN DE LA MUJER A TRAVÉS DEL DISCURSO.}

Lamentablemente, la mujer viene sufriendo una profunda discriminación y es víctima de la desigualdad desde los orígenes de la humanidad. Jamás ha sido considerada igual y mucho menos superior al hombre. Tal y como Alberdi y Matas (2002) nos explican en el segundo capítulo de su libro La violencia doméstica. Informe sobre los malos tratos a mujeres en España, no está del todo claro el origen del patriarcado como sistema de organización social, algunas teorías se apoyan en las diferencias biológicas entre hombres y mujeres, otras entre la diferenciación de tareas entre hombres y mujeres como forma de división del trabajo social. Lo que sí es cierto es que la forma del sistema del patriarcado es universal y se viene dando desde los principios de la humanidad.

Hay muchas maneras de dejar reflejada la discriminación que se profesa contra la mujer en nuestra sociedad, también excluidas a través del discurso."Se dice que los hombres y las mujeres no hablamos igual y además nosotras somos juzgadas de manera distinta, aunque digamos exactamente lo mismo que los hombres" (asegura Hidalgo) y nos explica que según Violi (1991) "el lenguaje es neutro, no solo porque quien habla deja en su discurso huellas de su propia enunciación, 
sino también porque la lengua inscribe y simboliza en el interior de su misma estructura la diferencia sexual de forma jerarquizada y orientada" (p.36).

Patrizia Violi, en su libro titulado El infinito singular, nos habla sobre las relaciones entre el lenguaje y el sexo. La autora parte de la convicción, fruto de su propia experiencia, de que existe un nexo entre estas dos instancias, sexo y lenguaje, que pone límites a la posibilidad de autoexpresión de las mujeres.

En el artículo titulado La comunicación verbal en la mujer de García Basauri ${ }^{15}$ introduce una cita, al comenzar dicho texto, de Sigmund Freud que viene a sintetizar y resumir en pocas palabras lo que las mujeres no deben permitir, esto es, abandonar nuestra lucha y darse por vencidas. La frase, que imaginamos que él pronuncia sin ni siquiera tener a la mujer en mente en ese preciso instante dice así: "No se puede saber hasta dónde se va a llegar: se empieza cediendo en las palabras; finalmente, se cede en la cosa". Referida a la mujer o no está claro que Basaurí sabe recogerla y animar con ella a darse por aludidas y no abandonarse.

A través de esta investigación, Basauri nos habla del sexismo en el lenguaje, así como también de las determinadas diferencias verbales existentes y que emplean hombres y mujeres a razón de su sexo. Además, ella hace hincapié en los diversos estereotipos que han sido creados, y en ocasiones mantenidos a través de décadas, sobre el comportamiento verbal de la mujer:

Además, Basauri demuestra que la antropóloga Ma Jesús Buxo Rey ilustra y establece las disimilitudes $^{16}$ existentes entre las capacidades del uso del lenguaje del niño y la niña, llegando a las siguientes conclusiones:

“las niñas, en las primeras edades, son lingüísticamente más adelantadas que los niños, tienen una habilidad especial para con la lengua y una discriminación auditiva mayor, características que afectan a otros comportamientos como la atención, la interacción social, de desarrollo de la necesidad comunicativa y el interés por la relación social." (1988, p. 109)

Encarnación Hidalgo también cita a esta antropóloga haciendo reflejo de que ella constata que existen un gran número de estereotipos y refranes alusivos al comportamiento lingüístico de la mujer en los que el paradigma es de desorden y del mal. Los temas de estos refranes son variados, muy diversos: el lenguaje de la mujer es indiscreto, el campo lingüístico de la mujer corresponde a un hablar por hablar, el lenguaje de la mujer es peligroso, otros refranes son juicios morales relativos a como deberían ser el comportamiento lingüístico de este sexo, etc.

\section{CONCLUSIONES}

A lo largo de esta investigación nos hemos familiarizado, o al menos hemos tomado una mayor conciencia de la sociedad en la que vivimos actualmente que, en algunos aspectos, especialmente en los que a la discriminación y violencia contra las mujeres se refiere, no se distingue en exceso de otras sociedades y épocas anteriores en las que las mujeres eran consideradas seres inferiores al varón y por tanto merecedoras absolutas de la discriminación, maltratos y abusos a los que debían resignarse en silencio.

Muchos son los aspectos que deben corregirse aún para poder seguir avanzando hacia un mundo en el que hombres y mujeres aprendan a convivir y lo hagan en igualdad. Para lograr la supervivencia humana, por el bien de todos/as, necesitamos seguir la batalla contra esta destrucción despiadada que desafortunadamente sigue profesándose hacía las mujeres por muchas décadas y siglos que pasen. 


\section{GÉNERO EN EL DISCURSO: DISCRIMINACIÓN. MALTRATO A LA MUJER}

\section{REFERENCIAS BIBLIOGRÁFICAS}

Alberdi, I. y Matas, N. (2002) "La violencia doméstica. Informe sobre los malos tratos a mujeres en España”. Barcelona: Publicación de la Fundación La Caixa, Colección de Estudios Sociales. Barcelona.

Arrom, S. (1988).Las mujeres de la ciudad de México, 1790-1857.Mexico Siglo XXI.

Aulagnier, P. (1975). La violencia de la interpretación. Buenos Aires: Amorrortu.

Buxo, M. J. (1988): Antropología de la mujer. Cognición, lengua e ideología cultural, Barcelona: Anthropos.

García, B. (1991). "La comunicación verbal en la mujer”. http://revistas.ucm.es/index.php/DIDA/article/view/DIDA9191110013A/20284 (recuperado el 23 de Mayo de 2016)

García, C. (2001). "Violencia de Género". Recuperado de: <htpp//www.psicoterapeutas.com /paginapersonal/concha/violenciadegenero.htm> ( recuperado el 5 de Julio de 2005).

Instituto de la Mujer. Ministerio del Interior, Ministerio de Asuntos sociales. (1991). Violencia contra la Mujer. Ministerio del Interior. Depósito Legal: M.27024-1991.

Suarez, M. (2004). Provocando la reflexión sobre el discurso "violencia contra la mujer. Brasilia.

Naciones Unidas. (1995) "Violencia Doméstica Contra la Mujer en América Latina y el Caribe: Propuestas para la Discusión". Santiago de Chile: Serie Mujer y Desarrollo.

Naciones Unidas (1996). Informe de la Cuarta Conferencia Mundial sobre la Mujer Beijing, 4 a 15 de septiembre de 1995. New York.

Suárez, M. (2004). Discurso, género y violencia intrafamiliar en la historia moderna de México ¿una memoria?. Disponible en el archivo de Tiempo y Escritura (recuperado (recuperado el 5 de Junio de 2014) http://www.azc.uam.mx/publicaciones/tye/violenciaintrafamiliarenlahistoria.htm.

Velázquez, S. (2003). Violencias cotidianas, violencia de género. Buenos Aires: Paidós.

Violi, P. (1991). El infinito singular, Madrid: Cátedra- Univ. de Valencia.

\section{WEBGRAFÍA}

www.azc.uam.mx/publicaciones/tye/violenciaintrafamiliarenlahistoria.htm www.malostratos.org/30\%20CIMTM\%20feminicidios\%20010.htm agendadelasmujeres.com.ar/notadesplegada.php?id=273

www.agende.org.br/docs/File/dados_pesquisas/violencia/provocando $\% 20$ reflexa0\%20obre $\% 2$

Oviolencia\%20-\%20Mireya\%20p\%20UNIFEM\%20completo\%20-\%20espanhol.pdf (consultado en Febrero, 2011).

http://revistas.ucm.es/edu/11300531/articulos/DIDA9393110071A.PDF

http://www.feminicidio.net/articulo/listado-feminicidios-y-otros-asesinatos-mujeres-cometidoshombres-espa\%C3\%B1a-2017

1 Profesora Titular de Lengua Inglesa y vicedecana de relaciones internacionales en la Universidad de Granada.

2 El Máster en Estudios de Género: Mujeres, Cultura y Sociedad proporciona una formación especializada en estudios de género a mujeres y hombres procedentes de distintas áreas de conocimiento y de diferentes ámbitos profesionales al objeto de que puedan contribuir a la equiparación de los sexos y con ello, a una sociedad más justa e igualitaria.

3 Artículo de Marcela Suárez publicado en internet en el año 2004.

4 Violencia contra la Mujer, Ministerio del Interior, Ministerio de Asuntos sociales. Depósito Legal: M.27024-1991. 
5 Licenciada en Psicología, Especialidad de Clínica y de la Salud, y especialista en Intervención Social con Mujeres.

6 Psicóloga especialista en violencia familiar.

7 Inés Alberdi Alonso es la actual Directora Ejecutiva del Fondo de las Naciones Unidas para las Mujeres (UNIFEM). Es Catedrática de Sociología de la Universidad Complutense de Madrid, donde enseña Sociología Política y Sociología de las Relaciones de Género. Natalia Matas, socióloga y especialista de las relaciones de género escribió junto a Alberdi el libro titulado $L a$ violencia doméstica. Informe sobre los malos tratos a mujeres en España.

8 Texto para Discusión Elaborado por Mireya Suárez Brasilia, mayo de 2004.

9 Profesora titular de la Universidad Autónoma Metropolitana, Ciudad de México.

10 Es miembro de la World Federation for Mental Health; del Comité Asesor del Foro de Psicoanálisis y Género de la Asociación de Psicólogos de Buenos Aires, y miembro fundador del Centro de Estudios de la Mujer, de Buenos Aires.

11 No hay más que recordar el caso de María Magdalena, considerada pecadora por estar con varios hombres, por lo que estos la apedreaban...

12 Profesora de Historia en la Universidad de Standford. Sus intereses de investigación incluyen la historia de América Latina social, el México moderno, las mujeres y la familia, y las relaciones entre Estados Unidos y América Latina.

13 http://www.feminicidio.net/articulo/listado-feminicidios-y-otros-asesinatos-mujeres-cometidoshombres-espa\%C3\%B1a-2017

14 Profesora titular de la Universidad Complutense de Madrid.

15 Véanse en el artículo La comunicación verbal de la mujer de Mercedes García Basauri (1991. Págs. 76-78). 
